\title{
ACERCA DEL CONDICIONAMIENTO SOCIOECONÓMICO DE LA LOCURA LLUCIA RAMIS Y OTRAS NARRADORAS ACTUALES
}

CRISTINA SANZ RUIZ

Universidad Complutense de Madrid cristina.sanz@ucm.es

RESUMEN: En este artículo se examina el papel protagonista de la locura como uno de los motivos más repetidos en la "novela de la crisis". A pesar de la disparidad de aproximaciones a la materia, la mayor parte de los autores plantea una relación de causalidad entre precariedad económica e inestabilidad mental, que se corresponde con lo demostrado por diversos estudios sociológicos y psicológicos. Hemos constatado, además, que las tres novelas que incorporan un enfoque más introspectivo han sido escritas por mujeres (Marta Sanz, Elvira Navarro y Llucia Ramis). Por último, utilizamos el caso particular de Las posesiones (2018) de Llucia Ramis para elaborar un análisis más exhaustivo.

PALABRAS CLAVE: novela de la crisis, precariedad, enfermedad mental, género, siglo XXI, Llucia Ramis. 


\section{ABOUT SOCIOECONOMIC CONDITIONING OF MADNESS Llucia Ramis and Other Contemporary Female Storytellers}

ABSTRACT: This paper examines the main role of madness as one of the most reiterative issues addressed by the "crisis novel." Despite the vast disparity in approaches, most authors draw a causal relation between economic precariousness and mental instability, which coincides with the results of sociological and psychological research. This article intends to demonstrate that female writers, exemplified by Marta Sanz, Elvira Navarro, and Llucia Ramis, reveal more introspective perspectives than male writers. For that purpose, the article analyzes in depth the particular case recounted in Ramis's Las posesiones (2018).

KEY WORDS: Crisis novel, precariousness, mental illness, gender, TwentyFirst Century, Spanish literature, Llucia Ramis.

$\mathrm{D}$ esde 2008, la crisis económica y sus efectos es uno de los temas que aparece con mayor frecuencia en la narrativa española. Han pasado más de diez años y la existencia de este fenómeno parece indiscutible (Sanz Villanueva, 2016; Valdivia, 2016; Claesson, 2019: 14): ya hablamos con cierta comodidad incluso de un subgénero concreto, la novela de la crisis. A pesar de los diversos enfoques y estilos que ofrece este conjunto de obras, en él se repiten una serie de motivos que coinciden con la actualidad económica y política de los últimos años, como si estos asuntos saltasen en picado de las páginas de los periódicos a las de las novelas; desahucios, despidos, desempleo o precariedad laboral figuran entre los más reiterados. Junto a estas cuestiones de la actualidad reciente, otra llama mucho la atención: sorprende la cantidad de veces que se hallan referencias a lo que llamaremos, con cierta laxitud, la locura; es decir, textos en los que se mencionan enfermedades mentales, sus síntomas o sus tratamientos psicoterapéuticos. Por ello, nos hemos preguntado si los autores de estas páginas entienden la inestabilidad psicológica como un rasgo más de la precarización vital. Queremos, en fin, saber por qué hay tanto loco suelto - discúlpeseme la desconsiderada expresión coloquial para tema tan grave - en la novela de la crisis y si, quizás, las enfermedades mentales actúan - en una lectura más profunda- como metáforas de la enfermedad social en que vivimos.

\section{Locura y crisis económica}

Antes ya del nacimiento de Alonso Quijano, la figura del loco había dado fértiles resultados en la tradición literaria, bien por la fascinación que provoca quien ve el mundo al revés, bien por las muchas posibilidades que este personaje, el loco lúcido, ofrece a la hora de desenmascarar verdades amargas (así lo atestigua una bien nutrida estirpe de graciosos teatrales). El linaje literario de quien vocifera a solas con su sombra y su quimera, por decirlo con el contundente verso de Machado, incluye personajes de muy diversa índole, pero lo que entendemos por loco en el lenguaje coloquial no tiene por qué corresponderse con alguna de las patologías recogidas por la American Psychiatric Association (APA) en su Diagnostic and Statistical Manual of Mental Disorders - más conocido por sus siglas, DSM-. En lo cotidiano, hablamos de locos y muchas veces nos referimos tan solo a personas imprudentes, extravagantes o poco convencionales. También sucede así en el lenguaje de las novelas. En otras ocasiones, la ficción presenta personajes con más que probables problemas de salud mental, pero no lo expresa de forma explícita (encarnan tal situación, por ejemplo, los antagonistas de la novela de Marta Sanz Amor fou). Estos casos - los de personajes raros y los que solo nos permiten intuir la enfermedad- no se tienen en cuenta para esta reflexión, ya que, más allá de nuestros conocimientos genéricos de la materia, no poseemos la formación necesaria para determinar los límites de lo patológico. Dicho análisis, que se revelaría de gran interés, requeriría el apoyo complementario de un especialista en salud mental que revisase las lecturas y orientase el uso de una metodología apropiada en su campo de estudio.

En un paciente trabajo de investigación aún en marcha sobre la narrativa testimonial española publicada entre 1998 y 2018 — un amplio cor- 
pus de un centenar de obras- hemos detectado, según se indicaba arriba, la abundante presencia de enfermos mentales y de alusiones a trastornos, tratamientos psiquiátricos y psicoterapéuticos. En un censo provisional y no exhaustivo, mencionan la salud mental de forma explícita al menos los siguientes autores: Javier Sáez de Ibarra (Fantasía lumpen, Tusquets, 2015), Recaredo Veredas (Deudas vencidas, Salto de página, 2014), Marta Sanz (principalmente en Clavícula, Anagrama, 2017; pero también en La lección de anatomía, RBA, 2008), Gabi Martínez (Las defensas, Seix Barral, 2017), Luis Artigue (Donde siempre es medianoche, Pez de plata, 2018), Alejandro López Andrada (El jardin vertical, Trifaldi, 2015), Esther Guillem (Bestseller, Círculo Rojo, 2013), Elvira Navarro (La trabajadora, Random House, 2014), Isaac Rosa (La habitación oscura, Seix Barral, 2013), Llucia Ramis (Las posesiones, Libros del asteroide, 2018), Rosario Izquierdo Chaparro (Diario de campo, Caballo de Troya, 2013), Santi Fernández Patón (Grietas, Lengua de Trapo, 2015), Marta Caparrós (Filtraciones, Caballo de Troya, 2015) o Miguel Ángel Ortiz (La inmensa minoría, Random House, 2014). Una nómina de narradores, salta a simple vista, sorprendentemente amplia, claro indicio de la importancia que cobra el motivo en la hora actual de nuestra narrativa.

Enseguida nos referiremos a las obras mencionadas, pero antes parece conveniente pararnos a considerar las conclusiones a las que han llegado distintos especialistas acerca de las relaciones entre salud mental y condicionamientos sociales (económicos, de raza, sexo o estatus). En concreto, la lectura del amplísimo tomo colectivo A Handbook for the Study of Mental Health. Social Contexts, Theories, and Systems editado por Scheid y Brown (2010) resulta fundamental para entender mejor el modo como estos problemas se representan en la ficción. Según se ha indicado, nuestro enfoque no pretende ser - ni podría serlo, con un mínimo de rigor- ni sociológico ni psicológico. Sin embargo, ambas disciplinas ofrecen una serie de datos y conclusiones muy ilustrativas para entender mejor cómo funciona la enfermedad mental, cómo la percibimos y de qué espejos se sirve la narrativa para reflejarla.

¿Qué se entiende, pues, en términos médicos, como "locura" o "trastorno mental"? Si partimos del punto de vista clínico, y según recuer- da la OMS, "hay una gran variedad de trastornos mentales, cada uno de ellos con manifestaciones distintas. En general, se caracterizan por una combinación de alteraciones del pensamiento, la percepción, las emociones, la conducta y las relaciones con los demás". Tales alteraciones tienen, a su vez, distintas posibles explicaciones, fundamentalmente de dos tipos: exógenas (externas o sociales) y endógenas (internas o genéticas). Son las exógenas las que más nos interesa considerar.

En la sociedad capitalista actual, el empleo, en muchos casos fuente primaria de identidad y satisfacción personal, puede implicar tanto efectos positivos como negativos (Lennon/ Limonic, 2010). Aquellos puestos en los que los empleados - en general, de clase trabajadora- tienen menor autonomía y control sobre sus tareas provocan una mayor tendencia a la depresión, al consumo de sustancias estupefacientes y a la baja autoestima (Karasek / Theorell, 1990). En la misma línea, también se ha demostrado la correlación entre desempleo e inestabilidad mental (Perrucci/ Perrucci, 1990) y, lo que es más importante, parece suficientemente probada la relación inversa entre clase social y ciertos tipos de trastornos mentales. Las clases sociales más bajas sufren mayores niveles de esquizofrenia, depresión, abuso de alcohol e incapacidad mental (Dohrenwend, 1990). También se notan diferencias de clase a la hora de buscar ayuda profesional. Las estadísticas arrojan datos interesantes: el nivel de estudios es clave para requerir este tipo de ayuda y, sin embargo, no queda claro que el nivel de renta afecte de igual modo (Pescosolido/ Boyer, 2010). Los estudiosos no parecen ponerse de acuerdo en los motivos subyacentes a esta relación inversa que se da entre nivel social e inestabilidad psicológica (Eaton/ Muntaner/ Sapag, 2010; Brown/ Scheid, 2010). En líneas generales, se ofrecen dos posibles modelos explicativos:

social causation or social selection. Social causation models postulate that those in lower status groups are subject to higher levels of stress such as poverty, unemployment, discrimination, and dangerous neighborhoods, and it is the higher levels of stress that account for higher levels of mental disorder. Social selection models focus on the individual and postulate that those 
with mental disorders will end up in the lower stratum of society (Brown/ Scheid, 2010: 166).

En resumen, una explicación sería que la precariedad (pobreza, desempleo...) provoca mayores niveles de estrés que derivan, a su vez, en el desarrollo de enfermedades mentales. O sea, se postula que es la preexistente desigualdad en la sociedad la que afecta al desarrollo del individuo. Por el contrario, hay quien considera que el proceso se da a la inversa: el padecimiento de una de estas "alteraciones cognitivas" dificulta el acceso al empleo y la estabilidad, lo cual provoca, en última instancia, mayores niveles de pobreza. En este enfoque, los rasgos inherentes al individuo son los que determinan su posición dentro del entramado social.

\section{El mundo, caos y locura}

Volvamos a la literatura. ¿Qué sucede cuando el mundo empieza a percibirse como caos y la locura parece teñirlo todo? Estos dos son también los caminos posibles (de lo social a lo individual o de lo individual a lo social) por los que pueden transitar los escritores de la crisis. Aun así, lo primero que constatamos en las narraciones del selecto corpus señalado es que ofrecen una forma de incorporar la enfermedad mental bastante variada. El abanico incluye desde simples menciones a las patologías - las más habituales, depresión y ansiedad-, hasta aquellas en las que la locura se erige en materia narrativa principal. Según vamos a ver, existen variedad de tonos. A veces, resulta distanciado y jocoso. Otras, se ofrece una perspectiva que pretende revelar el estrecho vínculo de causalidad entre enfermedad y condiciones materiales (ante la disyuntiva antes planteada, resulta lógico que el sujeto precario se sienta identificado con la explicación de la causalidad social).

Aunque la enfermedad mental se representa en general como algo negativo - un estigma contra el que luchar o con el que aprender a vivirexisten también testimonios que incorporan el modelo del loco-lúcido, por ejemplo, la protagonista quijotesca de Los libros repentinos de Pablo Gutiérrez o el Sabueso que investiga diversos misterios en Donde siempre es medianoche de Luis Artigue. No se trata, aun así, de un arquetipo dema- siado fecundo. En Artigue observamos ciertas resonancias del detective anónimo que alumbró Eduardo Mendoza con El misterio de la cripta embrujada (1978), con quien comparte inflexión desenfadada y cómica. La ironía y el sarcasmo aparecen también en Deudas vencidas de Recaredo Veredas y en Bestseller de Esther Guillem.

Bestseller y Donde siempre es medianoche incorporan como material narrativo, y desde esa perspectiva jocosa, las propias sesiones de terapia. El terapeuta llega a convertirse en un personaje relevante para la trama de la obra, casi como si se tratase de un alter ego de los personajes que les permite tener conversaciones sobre sí mismos o, en términos freudianos, disputas del yo con el superyo. La conversación con el psicólogo -en un tono mucho más serio- sirve de cierre de La trabajadora. Además de incorporarlo como personaje, el terapeuta juega un papel instrumental en la estructura narrativa de las novelas de Artigue, Guillem y Navarro. Las tres coinciden en incorporar el juego metanarrativo gracias al cual la novela que lee el lector resulta ser la novela que el personaje está escribiendo y que, a su vez, los personajes-autores comentan con sus respectivos psicólogos.

Como objeto de estudio, Bestseller no resulta demasiado atractiva, pues, a diferencia de otros autores y a pesar de sus ochocientas páginas, no queda claro adónde quiere llegar en realidad la autora. Rosa, la protagonista, ama de casa en paro, no soporta la actitud de su marido, Paco (también desempleado y con síntomas que apuntan hacia la depresión), y le pide que acuda a terapia. Este motivo sirve de excusa a Guillem para explicar que la crisis económica ha llenado de clientes el despacho del psicólogo, Esteban. Tras una primera (y única) sesión con Paco, Esteban decide que está ante un caso perdido y cree que no sirve de nada tratarle; le parece preferible que sea Rosa la paciente. A pesar de la cantidad de páginas que se dedican a esta subtrama (se plasman con detalle los diálogos de varias sesiones de terapia que más bien parecen charlas de café), no aporta mayor profundidad a la narración. Al final, todo se resuelve un poco a la manera de las comedias de enredo: como sea, pero con final feliz. Paco se anima, Rosa encuentra trabajo, vuelven a enamorarse y son felices. 
Un caso peculiar lo dibuja Las defensas de Gabi Martínez, que narra la historia de Camilo, un neurólogo especialista en enfermedades autoinmunes que sufre varios brotes violentos y debe ser ingresado en un psiquiátrico. Cada episodio de la vida de Camilo aparece acompañado de los acontecimientos políticos del momento, por lo que la novela ofrece un interesante retrato de nuestro país desde los años ochenta hasta la actualidad. No podemos decir en sentido estricto que se plantee una relación de causalidad entre lo histórico y lo psicológico, pero los brotes de Camilo tienen, como desencadenante, la competitividad y el estrés del trabajo, así como el mobbing laboral que sufre en un determinado momento. De algún modo, quedan así vinculados el relato histórico, la enfermedad mental — cuyo diagnóstico neurológico no se descubre hasta el final- y las condiciones propias del trabajador en el sistema del capitalismo avanzado que vivimos.

Cuando se plantea la pugna entre lo genético y lo social, los autores tienden a enfatizar el peso de las condiciones materiales. Por ejemplo, los protagonistas del relato "Atrevimiento" (recogido en Filtraciones) de Marta Caparrós (2015) sufren periodos de depresión que coinciden con largas temporadas como trabajadores en paro. No siempre queda tan claro, sin embargo, de qué lado cae la balanza. Esto sucede, entre otros textos, en El jardín vertical de Alejandro López Andrada, donde el narrador afirma: "mi exaltación anímica brutal me acabó conduciendo a una severa esquizofrenia que me costó superar más de dos años y, al final, tras mutarse en trastorno bipolar, dejó en mi interior secuelas irreparables" (34).

Las tres obras en las que más claramente se defiende la relación de causalidad entre la (in)estabilidad socioeconómica y la mental son las ya mencionadas La trabajadora de Elvira Navarro, Clavícula de Marta Sanz y Las posesiones de Llucia Ramis. Dicha inestabilidad surge, en parte, como consecuencia de la incertidumbre ante la veracidad de los relatos (tanto oficiales como individuales), que termina provocando la desconfianza en el propio lenguaje y sus funciones. A esta desconfianza (¿quién narra? ¿es verdad lo que nos cuenta?) se suma la fragmentación del discurso. La ausencia de linealidad es un modo de enunciación propio del nuevo sujeto precario que percibe el mundo como caos y ruptura.

Que se trate de tres novelas escritas por sendas mujeres sugiere una serie de preguntas cuya respuesta ha de buscarse también desde perspectiva de género. Si acudimos de nuevo a los estudios sociopsicológicos, no encontramos sorprendente que sean mujeres las que indaguen de modo más profundo e íntimo en estas cuestiones. Por suerte, ya no se acude a la teoría de la histeria femenina que copó los manuales de la medicina victoriana. Hoy contamos con suficientes datos para afirmar que, en términos cuantitativos, los trastornos mentales afectan al mismo porcentaje de hombres y mujeres (Brown/ Scheid, 2010; Rosenfield/ Smith, 2010). No obstante, se ha constatado una prevalencia de diagnósticos de trastornos de ánimo - depresión y ansiedad - en mujeres, mientras que en la población masculina la tendencia vira hacia los trastornos de personalidad y las adicciones (Brown/ Scheid, 2010; Rosenfield/ Smith, 2010). No están claras las causas que provocan estas diferencias de género, aunque algunos estudiosos apuntan a factores socioeducativos (Brown/ Scheid, 2010). Consecuencia de una educación tradicional anclada en roles de género estrictos y coercitivos (Nieva-de la Paz, 2009), las mujeres tienden a volcar los sentimientos negativos hacia el interior provocando inclinaciones autodestructivas. Las enfermedades de los hombres, en cambio, tienden a la externalización y, por ello, están relacionadas con comportamientos antisociales no introspectivos que resultan más problemáticos hacia otros que hacia ellos mismos (Rosenfield/ Smith, 2010: 260). Otro factor que ha sido considerado en los estudios que relacionan género y salud mental es el peso del trabajo, tanto remunerado como no remunerado. Las mujeres trabajadoras exhiben mayores síntomas de ansiedad y depresión cuando las responsabilidades del hogar caen enteras sobre sus hombros y no son compartidas con la pareja (Rosenfield/ y Smith, 2010: 262). Se ha constatado que las tareas domésticas afectan de modo diferente a la (in)estabilidad mental de amas de casa y mujeres trabajadoras. Estas últimas tienen menores niveles de depresión, probablemente debido a los beneficios del empleo en términos de satisfacción personal y social. Sin embargo, mantener el empleo y, a la vez, encargarse del hogar, puede derivar en mayores niveles de ansiedad (Lennon/ Limonic, 2010). Se ha observado, asimismo, una importante diferencia en cuanto al apoyo terapéutico recibido: las mujeres son más proclives a buscar ayuda y acudir más a la consulta del psicólogo 
(Pescosolido/ Boyer, 2010). No sorprende esta diferencia si pensamos en frases tan comunes como llorar es de niñas o sé un hombre que asocian la masculinidad a una fortaleza y esa fortaleza se mide en cuanto se es capaz de controlar (reprimir) las emociones.

Según lo expuesto, no parece casualidad que la enfermedad mental tenga una prevalencia tan significativa entre las novelas de la crisis ni que los textos que más ahondan en las raíces de las patologías psicológicas estén escritos por mujeres y tiendan a la introspección. Tampoco nos extraña que los escritores varones hablen de estas enfermedades a través de técnicas distanciadoras y/o disociadoras, dos de los mecanismos más comunes de defensa. Así se observa, por ejemplo, en la relación de Osmundo, el protagonista de Deudas Vencidas (Veredas, 2014), con los diversos psicoterapeutas por los que ha pasado; de uno de ellos llega a afirmar que "me generó ansiedad y que tu psiquiatra te genere ansiedad es equiparable a adquirir una infección hospitalaria" (25). Aún más evidente resulta la postura distanciadora de Sabueso, el narrador protagonista de Donde siempre es medianoche (Artigue, 2018), con respecto a la enfermedad mental que sufre:

Por eso mi psicoanalista — al que, a pesar de serme imprescindible, yo no ceso de poner apodos como Doctor Retranca Edípica, soy así de gilipollas- me ha hecho concluir que acabé como sabueso para tener de qué hablar con ellas (con las mujeres, se refiere). ¡Estoy enganchado al psicoanálisis! Ando algo loco. [...] La depresión, la angustia, los accesos de pánico, el sentimiento de culpa, la fotografía y no encontrar taxis cuando hace falta son cosas que se me dan bien. En efecto, soy un gilipollas psíquico... (19).

En La trabajadora, la enfermedad mental aparece como una consecuencia directa de la progresiva precarización del empleo. La tercera parte de la novela, de tan solo dos páginas, incorpora un diálogo de la narradora con su terapeuta que se corta abruptamente tras una frase que podríamos llamar, en términos de pragmática, enunciado performativo: "Si no logro superar la impresión de estar a punto de perder la cordura, esta podría ser la última frase del libro. Porque continuar si no ocurre nada resultaría redundante, ¿no?” (Navarro, 2014:155). La pregunta retórica “¿no?” anuncia el fin de la novela, que se termina, según se explica, porque la locura no ha sido superada. Esto se debe a que la enfermedad mental se produce como consecuencia de la inestabilidad; y la inestabilidad es el único rasgo estable del trabajo actual: "la situación se normalizó, o más bien se estabilizó en lo precario” (ibidem:153).

La precariedad, esa sensación de vivir sin agarres, es la que lleva a Marta Sanz a confesar, aunque sea con la ironía que la caracteriza, que nunca toma más de un ansiolítico diario, pero tampoco menos de uno al día. El título de esta obra, Clavícula, hace referencia a un dolor indeterminado que siente en dicho hueso del tórax. La hipocondría que este dolor desencadena (sumado a la preocupación por dejar de tener ingresos) es el resorte sobre el que construye el texto. Sanz coloca sus propios trastornos mentales en el centro de esta obra y se ríe de sí misma para cuestionar con ello ciertos discursos heredados. Con esta estrategia de burla íntima pretende contribuir a subvertir el relato hegemónico (objetivo que ya se había propuesto en sus anteriores producciones literarias (Sanz Ruiz, 2017)). Lo vemos, por ejemplo, cuando afirma, "voy a las consultas y me sonrío pensando lo caras que le salimos las locas a la seguridad social" (Sanz, 2017: 92 , subrayado mío). No se refiere a "los locos" - a los que suponemos igual de caros de tratar-, sino a "las locas" y lo hace porque sabe que su libro se inserta en una tradición literaria (cultural y social) donde la locura se presenta como rasgo característico de la feminidad. En ello hace hincapié pocas páginas después: "Somos tantas las locas. Tantas" (ibidem: 96). Sanz es consciente de la representación icónica de la locura asociada al género - quién no ha oído hablar de una histérica - y considera que su compromiso como escritora implica cuestionar los discursos asumidos y proponer, en la medida de lo posible, imágenes alternativas de mujer. Labor que, por otro lado, y como se apunta en el libro colectivo coordinado por Vilches-de Frutos y Nieva-de la Paz (2012), resulta compartida por un buen número de escritoras de los últimos dos siglos. Pero Marta Sanz no quiere caer en simplificaciones y nos parece que, por este motivo, propone una imagen de mujer forjada en la tensión de opuestos: un dolor físico (situado en la esfera de lo real) que se opone a un dolor psicológico (no 
constatable y, por ello, irreal); una Marta (individual) que desea huir del estigma contra una Marta (social) que quiere desarmarlo. El resultado es un texto cargado de paradojas, que se discute a sí mismo y reivindica el derecho a contradecirse: "Asumo el discurso de los hipocondriacos y me ciño a la mirada de lo que los demás esperan de mí. Pero hoy me rebelo. No soy una hipocondriaca. No estoy deprimida. Tengo un dolor. Una enfermedad. Lo reivindico. Me quejo" (86).

Estas breves reflexiones evidencian ya que las novelas señaladas - La trabajadora, Clavícula y Las posesiones - merecen análisis individualizados en mayor profundidad. Me centraré, por elegir una, en la más reciente de las tres, Las posesiones (Ramis, 2018). Frente a las obras de dos escritoras ya consagradas por público y crítica, Marta Sanz y Elvira Navarro, la de Ramis no cuenta todavía, que sepamos, con análisis en detalle, por lo que nos ha parecido oportuno dedicarle una particular atención. Y antes de hacerlo no estará de más señalar un rasgo que comparten las tres $y$, a nuestro entender, no por casualidad: se sostienen en un fuerte componente autoficcional o de inspiración autobiográfica. Como ya han señalado numerosos estudios (Caballé, 2002; Nieva-de la Paz, 2006), la presencia de lo íntimo en el relato político es un fenómeno propio de la escritura femenina que enlaza con el planteamiento del feminismo radical - the personal is political_, según ya se apuntó en una ocasión anterior (Sanz Ruiz, 2017).

\section{Corrupción, propiedad privada y locura: Las posesiones}

La mallorquina Llucia Ramis (1977) cosechó una crítica muy favorable con su, por ahora, última novela y despunta como una de las voces en verdad prometedora del panorama literario actual. Les possessions ganó en 2018 el III Premi Llibres Anagrama de Novel-la y se publicó ese mismo año en castellano (Las posesiones, Libros del asteroide). Según la apreciación de la propia autora, se trata "de una novel-la crítica, però no de denúncia" (Nopca, 2018). Con esta matización tajante, establece una clara frontera entre los términos "crítica" y "denuncia" que no nos resulta tan nítida (¿acaso la mera exposición de una crítica en cualquier foro público - un libro, en este caso- no implica una denuncia intrínseca?). La afirmación es discutible y podría ser aquí discutida, pero no la traemos a colación con ese propósito. Nos interesan estas declaraciones porque, de algún modo, reflejan su deseo por desvincularse de la literatura comprometida. En esa misma entrevista alude a su interés por abordar el tema de "la malaltia mental. Encara ara hi ha un tabú que impedeix que se'n parli obertament" (Nopca, 2018). Según veremos, incluso si dejamos la voluntad de denuncia al margen, lo innegable en esta novela es la directa relación de causalidad que se establece entre las condiciones externas - sociales- y las internas - mentales-.

La novela presenta estructura de retablo tríptico (un cuerpo central extenso guardado por dos partes breves) y yuxtapone tres ejes temporales y narrativos: 1993, 2007 y 2017.

(1) El preámbulo — sin título- sitúa la acción en 1993 y da cuenta de un suceso traumático consecuencia de uno de los primeros casos de corrupción en la España democrática. El empresario Benito Vasconcelos, arruinado y acusado de malversación de fondos, decide acabar con su vida y con las de su mujer y su hijo, Alejandro. El chico era compañero de instituto de la protagonista-narradora (cuyo nombre desconocemos) y el padre, socio del abuelo belga de ésta. Por ello el crimen tendrá una serie de consecuencias, económicas y emocionales que perdurarán a lo largo de los años sin llegar a evaporarse. Para poder saldar las deudas de su socio, el abuelo se ve obligado a malvender el caserío familiar, Can Meixura, espacio de la infancia de la narradora. El asesinato de su familia cometido por Benito y su posterior suicidio harán que la narradora, entonces aún adolescente, siga cuestionándose los porqués de la psique más de una década más tarde.

(2) En el cuerpo central de la novela -integrado, de nuevo, por tres partes (cada una de cuales se divide a su vez en varios capítulos) - , la recuperación de esta memoria se alterna con el relato de un episodio sucedido en 2007, clave en la vida de la protagonista: el delirio progresivo de su padre. Tras la jubilación, el padre decide dedicar su tiempo libre al activismo social y a adecentar su casa de vacaciones, el otro caserío familiar, Son Cors. Allí descubre que un vecino está construyendo un muro ilegal en el terreno colindante. Primero intenta pararlo escribiendo artículos en 
internet y, después, decide combatirlo a través de los tribunales. Su abogado le traiciona y fracasa así esta cruzada personal - precrisis - contra la especulación y recalificación. Así se describe el impacto de la noticia:

Tal vez descubrirá más adelante la trampa en la que ha caído. Pero ahora no. Ahora ha hecho crac. Lo ha oído perfectamente. No siente vergüenza, ni rabia, solo la caída, el vacío. No hay nada. Se acabó. [...] A su alrededor, todo se ha oscurecido. Está en el fondo de un pozo. Ya no recibe ningún tipo de información, todo rebota contra su cabeza y se pierde. No reconoce el entorno. Deja definitivamente de ser él. (Ramis, 2018: 202)

La deslealtad de su abogado supone un mazazo de realidad que le sumirá en una espiral de neurosis en la que pierde hasta su propia identidad:

Este no es mi padre, no dejo de repetirme. Soy incapaz de reconocerle, tan eufórico y ansioso, y con ese vacío abismal en los ojos, sin ningún respeto por la muerte ni por ninguno de los que ahora mismo estamos en sus manos, incluido él.

Ha tirado la toalla. El idealista, el creyente, el hombre convencido de que un mundo mejor era posible, el que confiaba en las personas, el que llevaba toda la vida luchando por la justicia social, ha sucumbido a la decepción. Nunca será un cínico. Él no puede serlo. Yo lo intento, pero no me sale.

Mi padre no es mi padre. No tengo ni idea de quién es. Un desconocido que, de pronto, ha soltado las riendas de su vida. (ibidem: 25-26)

Uno de los personajes de la novela, exnovio de la narradora, sugiere que el padre padece un trastorno de tipo quijotesco, esa locura lúcida de la que hablábamos, que sirve para arrojar luz sobre la historia: "Es como un Quijote del siglo XXI — dice Marcel—. Fíjate en que juega al borde del precipicio, pero no llega a perder la cordura. Utiliza los métodos del paranoico o del loco precisamente para iluminarnos" (ibidem: 27). Sin embargo, la comparación con el famoso hidalgo no parece muy apropiada. Locura e idealismo son sinónimos en don Quijote y, por tanto, curarse de la locu- ra significa renunciar al idealismo. La locura del padre no procede de su idealismo, sino de un golpe de realidad que lo desmorona, no hay lucidez en ese "crac" o "vacío abismal".

(3) Por último, el epílogo, titulado "El olvido", avanza hasta la actualidad de la narradora en 2017 (es decir, una década más tarde) para dar cuenta del devenir de algunos personajes. También recopila la nota de suicidio en la que Vasconcelos explicaba sus motivos (culpabilidad, desesperación, ruina, vergüenza) y explica la recuperación total de su padre:

Gracias a un buen psiquiatra que accedió a visitar, y gracias también a los ansiolíticos, también salió del pozo. El infierno, para mi padre, duró once meses. [...] Ni trastorno bipolar, ni demencia frontal, ni ninguna de esas posibilidades que tanto me había angustiado. Lo que tuvo fue algo que afecta a más del cinco por ciento de la población de este país, y va en aumento. Se calcula que una de cada cinco personas la padecerá, tarde o temprano. Una depresión. Nadie se atreve a mencionar la enfermedad. Está estigmatizada. Por eso nos cuenta tanto identificarla, entenderla y lo más importante: tratarla (ibidem: 245).

De este modo, el final del libro une las dos depresiones, la depresión del culpable y la depresión del idealista, ambas de causa externa aunque de signo opuesto. Igualmente opuesta es la (re)solución de las sendas enfermedades: suicidio y sanación. A pesar de ello, y paradójicamente, las dos se deben a un mismo detonante, la corrupción asociada al boom del ladrillo. Al yuxtaponer el final de las historias se retrata la doble cara de nuestra democracia (la de los especuladores y la de las víctimas) al tiempo que se inserta la crisis actual como parte de un proceso más largo y endémico, inherente al país, aquel estado místico del hombre del que se quejaba Gil de Biedma. De hecho, y como ahora desarrollaremos, la enfermedad adquiere en esta novela estatus de alegoría histórica. 
El término "possessió" que da título al libro debe entenderse en su carácter polisémico. Según el diccionari.cat, se trata de la "Acció de posseir” o "Cosa posseïda”, pero también "A Mallorca i a la regió de l'Ebre, porció gran de terreny de conreu, pertanyent a un propietari i dependent d'una casa situada dins el mateix terreny". Y por si no habíamos percibido la doble connotación, se asegura un personaje de explicarnos que "la palabra possessió no [es] una casualidad” (ibidem: 207). En la novela, la casa familiar Son Cors constituye a la vez una possessió y una cosa poseída, o sea, es a la vez una residencia y una propiedad heredable generadora de plusvalía; es un espacio de la nostalgia, pero también una posesión, resultado de la acumulación de capital de las generaciones previas.

Cuando heredan Son Cors, descuidado e inutilizado durante muchos años, su restauración se convierte en el proyecto de jubilación del padre. La construcción del muro en los alrededores de Son Cors, pretendido edén terrenal, destroza el equilibrio del — falso-locus amoenus y, con la ruptura física del espacio, se ejecuta la expulsión de dicho paraíso. A partir de ese momento, el padre sufre una depresión que, en términos de su hija, es un "infierno" (ibidem: 245). Igualmente idílica era la bonanza económica de España, tan falsa como prometedora ("Eran tiempos despreocupados, herencia de un pasado que parecía que iba a durar siempre", ibidem: 81). También hubo de quebrarse, en una grave depresión, tras la ruptura del espejismo en 2008.

El levantamiento del muro actúa como detonante de la locura, aunque en el fondo fuera "la traición, la maldad, su imposibilidad de aceptar que la injusticia a veces (casi siempre) gana - la dimensión del mundolo que derrotó a mi padre" (ibidem: 246). El padre asocia hasta tal punto el derrumbamiento de su mundo con la possesió que decide desprenderse de ella y regalársela a su hermana. Resulta significativo que este gesto de desposesión se realice no como venta sino como dádiva, es decir, sin generar plusvalía. De algún modo, desposeerse de la casa sin transformarla en capital es su modo de reencontrar el camino de la cordura. El proceso de

${ }^{1}$ Mantenemos el término en catalán, ya que, a pesar de la traducción al castellano en el título, la narradora mantiene esta y otras expresiones en su lengua materna. posesión-desposesión aparece, por tanto, directamente vinculado con el proceso locura-cordura, y sugiere así una lectura en clave dialéctica.

De este reajuste saldrá damnificada colateralmente quien había de heredar la casa. Cuando el padre pronuncia, con lentitud y morosidad, en estado casi cataléptico, "Vos... he... arrü̈nat... a tots..." (ibidem: 203) y solo es capaz de repetir esas palabras, está reconociendo el peaje pagado por su familia. La frase, reiterada, lenta, suena no sólo a manifestación de culpa, sino a plegaria que le permita conjurar la salvación. Al enterarse de la noticia, la narradora cambia la preocupación que le causaba que el trastorno mental de su padre, aún sin diagnosticar, fuera hereditario por la angustia hacia una herencia de tipo material:

¡Una casa! ¡Regalada! ¿Te suena algo llamado “especulación inmobiliaria"? ¿Tú sabes lo que vale ahora mismo una casa en Mallorca? ¡Lleváis toda mi puta vida diciéndome que no me endeude, que nada de hipotecas, que las propiedades solo acarrean problemas! ¿Y cuál es el resultado? Una mileurista que va empalmando contratos precarios y cruza los dedos para que no le suban el alquiler del piso (ibidem: 207).

Porque la herencia puede ser económica o psíquica y porque se puede heredar una casa como se puede heredar una enfermedad, la protagonista, al igual que la Isidora galdosiana, se convierte en una desheredada. En realidad, la hija de José Rufete (ingresado en el manicomio de Lavapiés) nunca fue desheredada porque la herencia nunca le perteneció. Sí recibió, en cambio, la herencia genética en forma de locura. En Las posesiones, la protagonista pierde $s u$ propiedad (la posesión) pero se libra - ¿gracias a ello? - de la enfermedad mental. Fijémonos en que se explicita el carácter no genético de la depresión que padece el padre: "Por factores exógenos', le dijo el doctor. No era algo que llevara dentro. No era genético. No es que tuviera una predisposición ni una tendencia al abismo" (ibidem: 246).

El enfado de la protagonista con su padre introduce otro de los motivos principales de la novela: el enfrentamiento generacional - hasta aparece una mención explícita al mito de matar al padre ("así fue como maté al padre. O por lo menos a una parte de él”, ibidem: 90)—. La disputa 
nos interesa porque trasciende la anécdota familiar para representar una pugna histórica entre quienes vivieron la transición y los que nacieron en esta. En un momento dado, la voz narrativa sitúa la acción a "las diez y media de la mañana del día que la Constitución cumple veintinueve años, uno menos que nosotros" (ibidem: 221). Se utiliza, pues, un referente histórico nada gratuito para informar de la edad de la narradora y sus interlocutores. De este modo, la historia de España se enlaza, por una parte, con la vida de la protagonista y, por otra, con la propia autora, hermanas de leche ambas de la Transición (recordemos: tanto Ramis como su protagonista han nacido en 1977). La autora ya había literaturizado la cuestión generacional en su ficción anterior, Coses que et passen a Barcelona quan tens 30 anys (2008). En Las posesiones esta problemática adquiere una dimensión más profunda que proviene, creemos, de la lectura dialéctica antes sugerida. No se trata solo de un conflicto entre padres e hijos, sino que se cuestiona la responsabilidad colectiva tanto de los babyboomers, -actores protagonistas en el cambio de paradigma propiciado tras la muerte de Franco-como de sus hijos - la generación X, a la que pertenecen Ramis y su narradora-, receptores del nuevo régimen. En la metáfora "hijos de la corrupción” (ibidem: 218) se traslada esa relación filial a un concepto abstracto. El hoy es la herencia de una madre-Estado negligente: se habla de una corrupción engendrada en los orígenes de la democracia, amamantada impunemente en la década de los noventa, desencadenante adicional a la crisis global sufrida en 2008, y cuyos perjuicios se siguen padeciendo en la actualidad. La lectura en clave histórica resulta un tanto desoladora: de los años de bonanza solo hemos heredado la corrupción, nuestra única constante histórica.

La imagen de la corrupción como el laberinto sin salida de nuestra democracia se refuerza gracias al estatismo que provoca el constante uso del presente verbal. Aunque las distintas tramas se desarrollan a lo largo de los casi cuarenta años de democracia, cada uno de los tres ejes temporales -1993, 2007, 2017- se narra en presente.

[1993] "Entonces, nos asalta un nombre. Es un nombre conocido y cercano. [...] Al teléfono, mi abuela contesta que sí, que acaba

de verlo. Dice que mi abuelo está consternado. No hace ni medio año que se jubiló" (ibidem: 10-11).

[2007] "Vuelvo a casa. A casa de mis padres. Voy despacio por unas calles que he recorrido tantas veces que las conozco de memoria. Cierro los ojos. Camino un trecho con los ojos cerrados" (ibidem: 75).

[2017] "Esta vez no me entero por la prensa ni por la televisión, sino antes, a través de un antiguo compañero del periódico" (ibidem: 243).

$\mathrm{Y}$ en ese eterno hoy es siempre todavía, dicho otra vez con verso machadiano, el tiempo pasa sin que nada cambie. Las posesiones propone un símil entre la inestabilidad económica y la inestabilidad mental que, a su vez, se percibe en su dimensión (a)temporal. El estatismo que refleja la novela corresponde a la atemporalidad que, siguiendo a Bauman/ Bordoni (2016), caracteriza el nuevo estado de crisis. Ya no existe confianza en un agente solucionador: no se cree ni en la capacidad del Estado ni en la del mercado para llevar a cabo esta tarea. Como consecuencia, el nuevo sujeto precario vive una coyuntura histórica sin precedentes, un impasse del que no cree que pueda salir. Así lo retratan también muchas novelas. La crisis parece haberse instalado de forma permanente en nuestras vidas y no sabemos si habrá ansiolíticos suficientes para superarla.

Recibido: 09/09/2019

Aceptado: 03/10/2019

\section{Referencias citadas}

Artigue, Luis (2018), Donde siempre es medianoche, Oviedo: Pez de plata. Bauman, Zygmunt y Carlo Bordoni (2016), Estado de crisis, Barcelona: Espasa.

Brown, Tony N. y Teresa L. Scheidn (2010), “The Social Context of Mental Health and Illness", en Teresa L. Scheid y Tony N. Brown (eds.), A Hand- 
book for the Study of Mental Health. Social Contexts, Theories, and Systems, Cambridge: Cambridge University Press, pp. 163-170.

Caballé, Anna (2002), "La autobiografía escrita por mujeres: los vacíos en el estudio de un género", en Nieves Baranda Leturio y Lucía Montejo Gurruchaga (eds.), Las mujeres escritoras en la historia de la literatura española, Madrid: UNED, pp. 141-152.

Caparrós, Marta (2015), Filtraciones, Barcelona: Caballo de Troya.

Claesson, Christian, coord. (2019), Narrativas precarias. Crisis y subjetividad en la cultura española actual, Asturias: Hoja de Lata.

Dohrenwend, B. P. (1990), "Socioeconomic Status (SES) and Psychiatric Disorders: Are the Issues Still Compelling?", Social Psychiatry and Psychiatric Epidemiology, 25, pp. 4-47.

Eaton, William W., Carles Muntaner y Jaime C. Sapag (2010), “Socioeconomic Stratification and Mental Disorder", en Teresa L. Scheid y Tony N. Brown (eds.), A Handbook for the Study of Mental Health. Social Contexts, Theories, and Systems, Cambridge: Cambridge University Press, pp. 226255.

Fernández Patón, Santi (2015), Grietas, Madrid: Lengua de Trapo.

Guillem, Esther (2013), Bestseller, Almería: Círculo Rojo.

Izquierdo Chaparro, Rosario (2013), Diario de campo, Barcelona: Caballo de Troya.

Karasek, R. y T. Theorell (1990), Healthy work: Stress, Productivity and the Reconstruction of Working Life, New York: Basic Books.

Lennon, Mary Clare y Laura Limonic (2010), "Work and Unemployment as Stressors", en Teresa L. Scheid y Tony N. Brown (eds.), A Handbook for the Study of Mental Health. Social Contexts, Theories, and Systems, Cambridge: Cambridge University Press, pp. 213-225.

López Andrada, Alejandro (2015), El jardín vertical, Madrid: Trifaldi.

Martínez, Gabi (2017), Las defensas, Barcelona: Seix Barral.

Navarro, Elvira (2014), La trabajadora, Barcelona: Random House.
Nieva-de la Paz, Pilar (2006), "Voz autobiográfica e identidad profesional: las escritoras españolas de la Generación del 27”, Hispania, 89.1, pp. 20-26.

--- (2009), "Modelos femeninos de ruptura en la literatura de las escritoras españolas del siglo XX: Concha Méndez (1898-1986), Carmen Martín Gaite (1925-2000) y Rosa Montero (1951-)", en Pilar Nieva-de la Paz (ed. y coord.), Roles de género y cambio social en la Literatura española del siglo XX. Amsterdam-Nueva York: Rodopi, pp. 108-131.

Nopca, Jordi (2018), “'M’he adonat que som el que hem anat perdent. Llucia Ramis guanya el premi Llibres Anagrama amb Les possessions”, Llegim, $<$ https://llegim.ara.cat/actualitat/Llucia-Ramis-guanya-Anagrama-novella_0_1943205769.html > [consulta: 1/06/2019].

OMS (s.f.), “Trastornos mentales”, OMS, <https:/www.who.int/topics/ mental_disorders/es/> [consulta: 1/02/2019].

Ortiz, Miguel Ángel (2014), La inmensa minoría, Random house.

Perrucci, C. y R. Perrucci (1990), "Unemployment and Mental Health: Research and Policy Implications", en J. Greenley (ed.), Research in Community and Mental Health, 6, Greenwich, CT: JAI Press, pp. 237-264.

Pescosolido Bernice A. y Carol A. Boyer (2010), "Understanding the Context and Dynamic Social Processes of Mental Health Treatment", en Teresa L. Scheid y Tony N. Brown (eds.), A Handbook for the Study of Mental Health. Social Contexts, Theories, and Systems, Cambridge: Cambridge University Press, pp. 420-438.

Ramis, Llucia (2018), Las posesiones, Barcelona: Anagrama.

Rosenfield, Sarah y Dena Smith (2010), "Gender and Mental Health: Do Men and Women Have Different Amounts or Types of Problems?", en Teresa L. Scheid y Tony N. Brown (eds.), A Handbook for the Study of Mental Health. Social Contexts, Theories, and Systems, Cambridge: Cambridge University Press, pp. 256-267.

Sanz, Marta (2017), Clavícula, Barcelona: Anagrama. 
Sanz Ruiz, Cristina (2017), "Marta Sanz y el contradiscurso del cuerpo: nuevos modelos de identidad en la Transición política”, Anales de la literatura española contemporánea, 42.1, pp. 123-44.

Sanz Villanueva, Santos (2016), "La literatura de la crisis: algunas conjeturas", Quimera. Revista de literatura, 394 (septiembre), pp. 16-19.

Scheid, Teresa L. y Tony N. Brown, eds. (2010), A Handbook for the Study of Mental Health. Social Contexts, Theories, and Systems, Cambridge: Cambridge University Press.

Valdivia, Pablo (2016), "Narrando la crisis financiera de 2008 y sus repercusiones", $452^{\circ}$ F. Revista de Teoría de la Literatura y Literatura Comparada, 15, pp. 18- 36.

Veredas, Recaredo (2014), Deudas vencidas, Madrid: Salto de página.

Vilches-de Frutos, Francisca y Pilar Nieva-de la Paz, coords. (2012), Imágenes Femeninas en la Literatura y las Artes Escénicas. Siglos XX y XXI, Philadelphia: Society of Spanish and Spanish-American Studies. 